\title{
FAKTOR YANG BERHUBUNGAN DENGAN IDWG DAN TEKANAN DARAH PASIEN HEMODIALIS DI RUMAH SAKIT SWASTA YOGYAKARTA
}

\section{RELATED FACTORS TO IDWG AND BLOOD PRESSURE IN HEMODIALYSIS PATIENTS AT PRIVATE HOSPITAL YOGYAKARTA}

\author{
Th Tatik Pujiastuti ${ }^{1 *}$ \\ 1*Stikes Panti Rapih Yogyakarta, Jl. Tantular No.401, Condongcatur, Kec. Depok, Kabupaten Sleman, \\ Daerah Istimewa Yogyakarta 55281, email: theresiatatikpujiastuti@yahoo.com
}

\begin{abstract}
Background: Patients with hemodialysis always increase every year. In Indonesia the number of active hemodialysis in 2016 increased by $72.29 \%$ from 2015 . The success of hemodialysis can be seen from the clinical condition of the patient, especially Interdialitic Weigh Giant (IDWG) and blood pressure. Therefore, it is very important to study related factors to IDWG and blood pressure in hemodialysis patients.

Objective: This study aims to describe related factors to IDWG and blood pressure in hemodialysis patients. Methods: This is a quantitative descriptive analytic research. Number of samples is 65 hemodialysis patients using random technique.

Result: Based on the Spearman correlation test showed that statistically, there is a correlation between gender and IDWG p 0,024<0,05, Exercise and Intradialysis diastolic blood pressure with p 0,000<0,05 ( $r=$ $0,46)$, comorbidities with Intradialysis diastolic blood pressure p $0,000<0,05$ and fluid intake with intradialysis systolic blood pressure p 0,031<0,05 ( $r=0.28)$.

Conclusion: It is assumed that gender, exercise, comorbidities and fluid intake are related to IDWG and blood pressure. Based on result of this study, this is important for nurses to take more intensive education about controlling cimorbidities, fluid intake and motivation to exercise in daily life.
\end{abstract}

Keywords: Hemodialysis, blood pressure, Interdialitic Weigh Giant (IDWG)

\section{PENDAHULUAN}

Hemodialisis merupakan salah satu metode dialisis. Dialisis adalah perpindahan cairan dan molekul melalui membran semipermiabel dari satu kompartemen menuju komparteman yang lain. ${ }^{1}$ Oleh karena itu, hemodialisis (HD) merupakan salah satu tindakan untuk menggantikan sebagian dari fungsi ginjal terutama fungsi ekskresi pada pasien Chronic Kidney Disease (CKD) tahap akhir atau disebut End Stage Renal Disease (ESRD). Menurut Stojanovic \& Stefanovic, 2007 hemodialisis merupakan live saving treatment bagi penderita End Stage Renal Disease (ESRD). ${ }^{2}$
Saat ini, pasien hemodialisis aktif di Indonesia jumlahnya semakin meningkat $72,29 \%$ dari tahun 2015 hingga 2016. ${ }^{3}$ Adapun angka kematian tertinggi mencapai $41 \%$ karena komplikasi kardiovaskuler. Berdasarkan penyakit penyerta diketahui bahwa $51 \%$ pasien hemidialisis dikarenakan hipertensi dan 28\% karena Diabelets Mellitus. Oleh karena itu keberhasilan tindakan hemodialisis menjadi fokus tindakan hemodialisis.

Keberhasilan tindakan hemodialisis jika mampu mengembalikan darah yang bersih kembali ke dalam tubuh artinya terjadi pembersihan toksin serta keseimbangan 
cairan dan elekrolit. ${ }^{4}$ Kualitas hemodialisis dilihat dari peningkatan perpindahan toksin uremik dari dalam tubuh. Beberapa aspek sebagai indikator peningkatan pergerakan toksin uremik dalam tubuh dalam tindakan hemodialisis antara lain penurunan berat badan interdialisis atau adanya pergerakan penumpukan cairan dalam tubuh, dan terhindar dari hipotensi intradialisis serta penurunan insiden hipertensi. ${ }^{5}$ Oleh karena itu berat badan interdislisis atau Interdialisis Weigh Giant (IDWG) dan tekanan darah merupakan indikator penting yang menentukan keberhasilan tindakan pada pasien hemodialisis.

Tekanan darah yang optimal merupakan indikator penting dalam keberhasilan tindakan hemodialisis. ${ }^{6}$ Tekanan darah pada pasien hemodialisis dipengaruhi oleh kondisi hipervolemis dan perubahan elastisitas vaskuler akibat proses patologis penyakitnya. Seharusnya melalui tindakan hemodialsis kondisi tekanan darah dapat mencapai kondisi yang optimal. Selain tekanan darah, indikator penting lain adalah ketercapaiannya IDWG yang normal yaitu tidak melebihi $5 \%$ dari berat badan keringnya. Pengkajian dan pengendalian tekanan darah dan volume cairan yang diukur melalui IDWG merupakan aspek penting dalam tindakan hemosialisis yang harus dicapai secara optimal. ${ }^{7}$ Intake cairan mempunyai pengaruh terhadap IDWG dan tekanan darah pada pasien hemodialisis. ${ }^{8}$ Selain itu, exercise atau latihan mempunyai peranan dalam mengendalikan teknan darah pasien hemodialisis. ${ }^{9}$ Tekanan darah berhubungan dengan exercise. ${ }^{10}$ Secara teori, faktor yang dapat meningkatkan keberhasilan hemodialisis di antaranya meningkatkan kualitas dializer dan penentuan dosis dialisis yang tepat, serta tindakan lain seperti penatalaksanaan diet, restriktif cairan yang adekuat, exercise dan medikasi yang sesuai. ${ }^{11}$

Berdasarkan data dari Rekam Medis salah satu Rumah Sakit swasta di Yogyakarta, kunjungan pasien hemodialisis selalu meningkat setiap tahunnya. Pada tahun 2015 - 2016 peningkatan kunjungan mencapai 14,59\%. Data tersebut menunjukkan bahwa hemodialisis (HD) menjadi trend yang semakin meningkat. Hasil studi pendahuluan yang dilakukan melalui wawancara kepada kepala unit dan perawat yang bertugas di Unit Hemodialisa Rumah Sakit tersebut, tindakan hemodialisis dilaksanakan secara rutin sesuai prosedur yang telah ditetapkan. Perawat belum mengembangkan tindakan keperawatan yang selama ini dilakukan untuk memperbaiki kondisi pasien terutama yang berkaitan dengan aspek pengendalian tekanan darah dan IDWG yang merupakan indikator penting dalam meningkatkan efektivitas tindakan hemodialisis. Keterlibatan aktif pasien untuk menjaga agar tekanan darah dan IDWG normal seperti melakukan exercise, restriktif cairan dan sebagainya belum dikembangkan secara optimal namun 
masih dalam batas edukasi yang rutinitas. Fenomena tersebut merupakan hal baru yang perlu diteliti karena setelah mengetahui faktor-faktor yang berhubungan dengan IDWG dan tekanan darah pasien hemodialisis, perawat akan akan dapat mengidentifikasi tindakan keperawatan yang mempunyai makna yang positif dan meningkatkan fungsi hemodialisis yang berimplikasi pada kualitas atau adekuasi tindakan hemodialisis untuk meningkatkan kualitas hidup penderita Chronic Kidney Disease (CKD) yang mengalami hemodialisis.

Berdasarkan latar belakang di atas, maka tampak adanya masalah yaitu factorfaktor apakah yang berhubungan dengan IDWG dan tekanan darah pasien hemodialisis. Oleh karena itu peneliti ingin mengetahui faktor-faktor yang berhubungan dengan IDWG dan tekanan darah pasien hemodialisis agar tercapai kondisi optimal proses hemodialisis sehingga tercipta derajat sehat yang optimal bagi pasien hemodialisis yang berujung pada peningkatan kualitas hidup pasien dengan hemodialisis.

\section{BAHAN DAN CARA PENELITIAN}

Penelitian ini merupakan penelitian deskriptif analitik kuantitatif yang bertujuan mengetahui factor-faktor yang berhubungan dengan IDWG dan tekanan darah pada pasien yang menjalani hemodialisis.

Penelitian dilakukan di unit Hemodialisis pada bulan September 2017-Agustus 2018 dengan melibatkan 65 responden dengan kriteria pasien yang telah dilakukan hemodialisis rutin minimal 2 kali seminggu selama minimal 3 bulan dengan tanpa gangguan kardiorespirasi yang diambil secara acak. Pengambilan data dilakukan dengan menggunakan lembar observasi dan catatan harian. Data dianalisis secara univariat menggunakan statistik deskriptif dan bivariat menggunakan korelasi spearman untuk mengetahui factor-faktor yang berhubungan dengan IDWG dan tekanan darah.

\section{HASIL DAN PEMBAHASAN}

Tabel 1. Karakteristik Responden Berdasarkan Usia $(n=65)$

\begin{tabular}{cccc}
\hline No & $\begin{array}{c}\text { Karakteristik } \\
\text { Usia }\end{array}$ & Frekuensi & $\begin{array}{c}\text { Persenta } \\
\text { se }(\%)\end{array}$ \\
\hline 1 & $20-40$ tahun & 19 & 29,2 \\
2 & $41-65$ tahun & 39 & 60 \\
3 & $>65$ tahun & 7 & 10,8 \\
\hline & Jumlah & 65 & 100 \\
\hline
\end{tabular}

Sumber : Data primer, 2017

Berdasarkan tabel 1 di atas diketahui bahwa jumlah terbesar responden adalah berusia 41 - 65 tahun yaitu 39 orang (60\%). Data ini menunjukan bahwa sebagian besar penderita Chrinic Kidney Disease (CKDI yang mengalami tindakan hemodialisis berada pada usia dewasa lanjut dan lansia awal, di mana pada usia tersebut seseorang mulai mengalami degeneratif dan mudah terjadi gangguan dalam sistem tubuhnya. ${ }^{12}$ Pada usia lebih dari 40 tahun akan terjadi proses hilangnya beberapa nefron. Pertambahan umur dalam setiap dekade diperkirakan 
terjadi penurunan fungsi ginjal sekitar 10 $\mathrm{ml} /$ menit/1,73 $\mathrm{m}^{2}$. Berdasarkan perkiraan tersebut, jika telah mencapai usia dekade ke 4, dapat diperkirakan telah terjadi kerusakan ringan, yaitu dengan nilai Glomerulus Filtrasi Rate (GFR) 60-89 ml/menit/1,73 $\mathrm{m}^{2}$ dan terjadi penurunan fungsi ginjal sekitar $10 \%$ dari kemampuan ginjal.

Tabel 2. Karakteristik Responden Berdasarkan Jenis Kelamin $(n=65)$

\begin{tabular}{clrr}
\hline No & $\begin{array}{l}\text { Karakteristik } \\
\text { Jenis Kelamin }\end{array}$ & Frekuensi & $\begin{array}{c}\text { Persentase } \\
\text { (\%) }\end{array}$ \\
\hline 1 & Perempuan & 25 & 38,5 \\
2 & Laki - Laki & 40 & 61,5 \\
\hline & Jumlah & 65 & 100 \\
\hline
\end{tabular}

Sumber : Data primer, 2017

Berdasarkan Tabel 2 di atas diketahui bahwa jumlah terbesar responden adalah laki-laki yaitu 40 orang $(61,5 \%)$. Berdasarkan data tersebut diketahui bahwa sebagian besar penderita CKD yang menjalani hemodialisis adalah laki-laki, maka diasumsikan bahwa jenis kelamin laki-laki mempunyai kecenderungan lebih besar untuk terjadi CKD sehingga memerlukan tindakan hemodialisis. Pola hidup tidak sehat seperti merokok, kurang akitivitas dan adanya penyakit seperti penyerta diabetes merupakan faktor yang diduga menyebabkan laki-laki lebih banyak menderita CKD sehingga harus hemodialisis. ${ }^{13}$ Selain itu, perkembangan penyakit ginjal pada wanita lebih lambat disebabkan oleh pola makan, perbedaan struktur ginjal, respons hemodinamik terhadap stress dan hormon seks. Beberapa studi menyatakan bahwa hormon seks wanita seperti estradiol berperan menghambat progesitas penyakit ginjal. $^{14}$

Tabel 3. Karakteristik Responden Berdasarkan Lama Menjalani Hemodialisis $(n=65)$

\begin{tabular}{clcc}
\hline No & $\begin{array}{l}\text { Karakteristik } \\
\text { Lama } \\
\text { Hemodialisis }\end{array}$ & Frekuensi & $\begin{array}{c}\text { Persentase } \\
(\%)\end{array}$ \\
\hline 1 & $<2$ tahun & 17 & 26,2 \\
2 & $2-4$ tahun & 27 & 41,5 \\
3 & $>4$ tahun & 21 & 32,3 \\
\hline & Jumlah & 65 & 100 \\
\hline
\end{tabular}

Sumber : Data primer, 2017

Berdasarkan tabel 3 di atas diketahui bahwa lama menjalani hemodialisis terbesar responden adalah $2-4$ tahun yaitu 27 orang $(41,5 \%)$. Data ini menunjukkan bahwa tindakan hemodialisis mampu mempertahankan hidup pasien hingga 2 - 4 tahun, dan setelah lebih dari 4 tahun tampak penurunan jumlah pasien.

Tabel 4. Karakteristik Responden Berdasarkan exercise dan asupan cairan $(n=65)$

\begin{tabular}{llll}
\hline No & \multicolumn{1}{c}{ Variabel } & Mean & \multicolumn{1}{c}{ SD } \\
\hline 1 & Exercise & 18,08 & 16,29 \\
2 & Asupan Cairan & 720 & 358,6 \\
\hline
\end{tabular}

Berdasarkan tabel 4 di atas dapat dianalisis sebagai berikut :

a. Berdasarkan statistik diketahui bahwa rata-rata waktu exercise interdialisis yaitu $18,08 \pm 16,29$ menit/hari. Berdasarkan data di atas, diasumsikan bahwa responden melakukan exercise atau kegiatan latihan paling lama 34,37 menit. Exercise dinyatakan pula sebagai faktor penting yang mendukung keberhasilan hemodialisis. Exercise meningkatkan 
volume maksimal oksigen $\left(\mathrm{VO}_{2}\right) \quad(95 \%$ confidence interval 3.86, 6.59, $\mathrm{p}<0,00001)$ dan menunjukkan kenormalan heart rate $(95 \%$ confidence interval $\quad 8.3, \quad 24.3, \quad \mathrm{p}<0,0001) .{ }^{15}$ Dinyatakan pula bahwa exercise signifikan memperbaiki massa tubuh, kekuatan otot dan tulang $\mathrm{p}<0,0001$. Selain itu exercise intra dan interdialisis meningkatkan kualitas hidup ( $95 \% \mathrm{Cl}$ 27.8, -5.5, $p=0,01)$. Oleh karena itu, exercise merupakan hal yang perlu diperhatikan, minimal 30 menit/hari. ${ }^{15}$

b. Berdasarkan statistik diketahui bahwa rata-rata asupan cairan yaitu $720 \pm$ $358,6 \mathrm{cc} /$ hari. Berdasarkan data di atas diasumsikan bahwa asupan cairan paling sedikit 361,4 cc/hari dan 1,08 L/hari. Asupan cairan merupakan faktor penting yang mempengaruhi adekuasi hemodialisis karena asupan cairan yang lebih sedikit atau sesuai dengan yang seharusnya dapat mempertahankan Interdialytic Weight Giant (IDWG) normal yang dalam penelitian ini disebut variabel berat badan. Pembatasan asupan cairan merupakan faktor yang penting mempengaruhi peningkatan berat badan IDWG. Meskipun demikian, IDWG juga sangat dipengaruhi oleh dosis ultrafiltrasi pencapaian Dry Weight saat proses hemodialisis. ${ }^{16}$ IDWG merupakan berat badan di antara dialisis yang dihitung dengan mengurangkan berat badan predialisis dengan berat badan posdialisis sebelumnya. Peningkatan IDWG merupakan indikasi ketidakberhasilan hemodialisis. Pasien yang memiliki IDWG yang baik memiliki angka kematian yang lebih rendah, yaitu sebesar $65,4 \%$ sampai $66,7 \%{ }^{17} \mathrm{Hal}$ ini menunjukkan bahwa asupan cairan yang baik (sesuai pembatasan) mempengaruhi IDWG yang dimiliki responden dan berpotensi menimbukan kualitas hidup yang kurang baik dan miningkatkan resiko kematian. ${ }^{17}$

Tabel 5. Karakteristik Responden Berdasarkan Penyakit Penyerta $(n=65)$

\begin{tabular}{clcc}
\hline No & $\begin{array}{l}\text { Karakteristik } \\
\text { Lama } \\
\text { Hemodialisis }\end{array}$ & Frekuensi & $\begin{array}{c}\text { Persentase } \\
\text { (\%) }\end{array}$ \\
\hline 1 & Hipertensi & 19 & $29,2 \%$ \\
2 & DM & 6 & $9,2 \%$ \\
3 & Hipertensi dan & 6 & $9,2 \%$ \\
\hline 4 & DM & 4 & $6,2 \%$ \\
\hline 5 & Lain-lain & 30 & $46,2 \%$ \\
\hline & Tidak ada & 65 & 100 \\
\hline
\end{tabular}

Sumber : Data primer, 2017

Berdasarkan data di atas diketahui bahwa hampir separu $(46,2 \%)$ responden tidak mempunyai penyakit penyerta dan ada $29,2 \%$ atau 19 responden mempunyai hipertensi.

Berdasarkan tabel 6 di bawah, diketahui bahwa ada korelasi atau hubungan antara jenis kelamin dengan IDWG p 0,024<0,05, Exercise dengan Tekanan Darah Diastolik Intradialisis p 0,000<0,05, penyakit penyerta dengan Tekanan Darah Diastolik Intradialisis p $0,000<0,05$, dan asupan cairan dengan Tekanan darah sistolik intradiaisis p 0,031< 0,05 . Tampak bahwa Jenis kelamin, exercise, asupan cairan dan penyakit penyerta 
mempunyai korelasi dengan salah satu indikator keberhasilan tindakan hemodialisis.

\begin{tabular}{|c|c|c|c|c|c|}
\hline \multirow[t]{2}{*}{ Variabel } & \multicolumn{5}{|c|}{ Korelasi } \\
\hline & $\begin{array}{c}\text { IDW } \\
\text { G }\end{array}$ & $\begin{array}{l}\text { TDS } \\
\text { intra }\end{array}$ & $\begin{array}{l}\text { TDD } \\
\text { Intra }\end{array}$ & $\begin{array}{c}\text { TDS } \\
\text { pasca }\end{array}$ & $\begin{array}{c}\text { TDD } \\
\text { pasca }\end{array}$ \\
\hline Usia & 0,25 & 0,682 & 0,061 & 0,816 & 0,627 \\
\hline $\begin{array}{l}\text { Jenis } \\
\text { Kelamin }\end{array}$ & $\begin{array}{c}0,024 \\
(r=0, \\
282)\end{array}$ & 0,232 & 0,212 & 0,108 & 0,643 \\
\hline $\begin{array}{l}\text { Lama } \\
\text { hemodiali } \\
\text { sis }\end{array}$ & 0,29 & 0,982 & 0,378 & 0,431 & 0,612 \\
\hline Exercise & 0,22 & 0,432 & $\begin{array}{c}0,000 \\
(r=0 \\
46)\end{array}$ & 0,521 & 0,298 \\
\hline $\begin{array}{l}\text { Asupan } \\
\text { cairan }\end{array}$ & 0,093 & $\begin{array}{c}0,031 \\
(r=0 . \\
28)\end{array}$ & 0,301 & 0,256 & 0,303 \\
\hline $\begin{array}{l}\text { Penyakit } \\
\text { Penyerta }\end{array}$ & 0,241 & 0,282 & $\begin{array}{c}0,005 \\
(r=0, \\
34)\end{array}$ & 0,064 & 0,757 \\
\hline
\end{tabular}

Diketahui bahwa ada hubungan signifikan antara jenis kelamin dengan IDWG dengan kekuatan hubungan $r=0,282$. Secara statistik hemodialisis banyak terjadi pada lakilaki dikarenakan pola hidup yang kurang baik seperti merokok dan kemungkinan terjadi penyakit penyerta. ${ }^{13}$ Belum banyak referensi yang menyatakan bahwa jenis kelamin berpengaruh terhadap IDWG, namun berdasarkan kajian bahwa CKD banyak terjadi pada laki-laki maka dapat diasumsikan bahwa jenis kelamin laki-laki biasanya kurang patuh terhadap restriktif cairan sehingga IDWG menngkat dan kurang terkendali. Hal tersebut dapat dikaitkan bahwa sebagian besar responden adalah laki- laki dan dengan data penghitungan rata - rata IDWG yang diidentifikasi dari selisih berat badan sebelum dialisis dan sesudah dialisis pada periode sebelumnya yaitu 2,57 $\pm 1,14$ kilogram, yang seharusnya IDWG dipertahankan dari berat badan setelah hemodialisis periode sebelumnya atau $1-2 \mathrm{~kg}$ selama perode interval Hemodialisis. ${ }^{18} \mathrm{Hal}$ ini didukung oleh Riyanto (2011) yang menyatakan bahwa pasien yang memiliki IDWG $>1,5 \mathrm{~kg}$ mempunyai resiko kematian lebih tinggi.

Secara statistik diketahui bahawa ada hubungan yang signifikan antara Exercise dengan Tekanan Darah Diastolik Intradialisis p $0,000<0,05$. Adapun kekuatan hubungannya adalah $r=0,46$ artinya cukup kuat. Exercise bertujuan untuk meningkatkan kekuatan otot, meningkatkan endurance, dan mempertahankan mobilitas sendi. ${ }^{19}$ Exercise bertujuan untuk menambah fungsi semua sistem tubuh, yang meliputi kemampuan endurance pada sistem kardiovaskuler, meningkatkan fleksibilitas dan integritas tulang dan otot, mempertahankan dan mengontrol berat badan untuk meningkatkan body image, dan meningkatkan psychological well-being. ${ }^{20}$ Exercise yang dilakukan secara teratur dan terus menerus mempunyai efek meningkatkan fungsi seluruh sistem tubuh. Efek exercise bagi tubuh, meliputi sistem kardiovaskuler, sistem respirasi, sistem metabolik, sistem muskuloskeletal, toleransi aktivitas, faktor psikososial. Exercise sangat menunjang fungsi sistem kardiovaskuler dengan meningkatkan cardiac output dan memperbaiki venous return, memperbaiki kontraksi miokardium dan menurunkan 
resting heart rate. Hal tersebut mampu mempertahankan tekanan diastolik terutama selama intradialisis. Salah satu indikator hemodialisis adalah terkontrolnya tekanan darah dalam batas normal selama dan sesudah hemodialisis. ${ }^{21}$

Secara statistik diketahui pula bahwa ada hubungan yang signifikan antara penyakit penyerta dengan Tekanan Darah Diastolik Intradialisis p 0,000 $<0,05$. Berdasarkan data penelitian diketahui bahwa ada $29,2 \%$ responden mengalami hipertensi. Ketika seseorang mengalami hipertensi, maka status pembuluh darah mengalami penurunan kemampuan dalam beradaptasi dengan perubahan hemodinamik tubuh. kondisi ini dapat menimbulkan ketidakstabilan tekanan darah. Pada saat hemodialisis, tubuh mengalami penarikan sejumlah volume yang signifikan mempengaruhi homeostasis tubuh akibat ultrafiltrasi. Ketika responden mengalami penyakit penyerta hipertensi, maka penyesuaian sistem kardiovaskuler tidak optimal seperti ketika tidak hipertensi. Tekanan darah diastolik intradialisis yang tidak normal menandakan tidak adekuasi hemodialisis. Hal ini sesuai yang disampaikan oleh Grange et al. yang menyatakan bahwa salah satu indikator hemodialisis adalah terkontrolnya tekanan darah dalam batas normal selama dan sesudah hemodialisis. ${ }^{21}$

Secara statistik diketahui bahwa ada hubungan yang signifikan antara asupan cairan dengan Tekanan darah sistolik intradiaisis p 0,031<0,05, dengan kekuatan hubungan $r=0,28$ yang artinya cukup kuat. Asupan cairan merupakan faktor penting yang mempengaruhi adekuasi hemodialisis karena asupan cairan yang lebih sedikit atau sesuai dengan yang seharusnya dapat mempertahankan Interdialytic Weight Giant (IDWG) normal yang dalam penelitian ini disebut variabel berat badan. Pembatasan asupan cairan merupakan faktor yang penting mempengaruhi peningkatan berat badan Interdialytic Weight Giant (IDWG). Meskipun demikian, IDWG juga sangat dipengaruhi oleh dosis ultrafiltrasi pencapaian Dry Weight saat proses hemodialisis. $^{16}$ IDWG merupakan berat badan di antara dialisis yang dihitung dengan mengurangkan berat badan predialisis dengan berat badan posdialisis sebelumnya. Peningkatan IDWG merupakan indikasi ketidakberhasilan hemodialisis. Menurut Riyanto, pasien yang memiliki IDWG yang baik memiliki angka kematian yang lebih rendah, yaitu sebesar $65,4 \%$ sampai $66,7 \% .{ }^{17} \mathrm{Hal}$ ini menunjukkan bahwa asupan cairan yang baik (sesuai pembatasan) mempengaruhi IDWG yang dimiliki responden dan berpotensi menimbukan kualitas hidup yang kurang baik dan miningkatkan resiko kematian.

Selain dikaitkan dengan IDWG, asupan cairan akan mempengaruhi volume vaskuler. Oleh karena itu, pada pasien hemodialisis dilakukan restriktif cairan agar volume 
vaskuler terkendali dan tekanan darah dapat dipertahankan dengan optimal. Berdasarkan statistik, rata-rata asupan cairan pada responden yaitu $720 \pm 358,6 \mathrm{cc} /$ hari. Diketahui pula bahwa asupan cairan paling sedikit 361,4 cc/hari dan paling banyak 1,08 L/hari. Data ini dapat diasumsikan bahwa restriktif cairan masih belum terkendali. Asupan cairan yang diharapkan adalah $500 \mathrm{cc}$ ditambah jumlah urin yang keluar. Pada kondisi umum, rata-rata $600 \mathrm{cc}$. Diasumsikan pula bahwa tekanan darah terutama sistolik juga tidak normal dengan kondisi tersebut. Cairan sangat berpengaruh menentukan sistolik karena retensi cairan pada vaskuler akan menimbulkan resistensi vaskuler yang meningkatkan tekanan darah sistolik.

\section{KESIMPULAN}

Berdasarkan hasil penelitian diketahui bahwa faktor-faktor yang berhubungan dengan tekanan darah pada pasien hemodialisis adalah exercise, penyakit penyerta, asupan cairan. Sedangkan faktor yang berhubungan dengan IDWG adalah jenis kelamin.

\section{TERIMA KASIH}

1. Semua pasien hemodialisis yang telah bersedia menjadi responden.

2. Bapak Agustinus Dalmasius, S. Kep., Ns, kepala ruang unit hemodialisa yang telah terlibat dalam proses penelitian.
3. Ketua STIKes Panti Rapih yang telah memberikan dukungan dalam proses penelitian.

\section{KEPUSTAKAAN}

1. Lewis, Sharon L., Dirksen, Shannon R., Heitkemper, Margareth M., Bucher, L., Camera, Ian M. Medical Surgical Nursing: Assessment and Managemant of Clinical Problems. USA: Elseiver, Mosby; 2011

2. Stojanovic, M., Stefanovic, V. Assessment of Health-related Quality of Life in Patients Treated With Hemodialysis in Serbia: Influence of Comorbidity, Age, and Income. Journal Artificial Organs. January 2007; Volume 31 (1): 53-60.

3. Indonesian Renal Registry (IRR). 9th Report of Indonesian Renal Registry. Indonesian: 2016

4. Smeltzer, S. C \& Bare. Keperawatan Medikal-Bedah Brunner \& Suddarth. 12 Ed. Jakarta: EGC; 2014

5. Maheshwari, V., Samavedham, L., Rangaiah, Gade P., Loy, Y., Ling, Lieng H., Sethi, S., Leong Titus L. W. Comparison of toxin removal outcomes in online hemodiafiltration and intra-dialytic exercise in high-flux hemodialysis : A prospective randomized open-label clinical study protocol. BMC Nephrology. 2012; 13:156.

6. Bakris et.al. Intensive Hemodialysis, Blood Pressure, and Antihypertensive Medication Use. Am J Kidney Dis. 2016: 68(5)(suppl 1); S15-S23

7. Jindal, K. et al. Hemodialysis Adequacy in Adults. J Am Soc Nephrol.2006; 17: S1S27

8. Sutherland. Fluid Balance on Haemodialysis. Inggris: Oxford University Hospitals; 2015

9. Qui et.al. Physical Exercise and Patients with Chronic Renal Failure: A MetaAnalysis. BioMed Research International.2017; Volume 2017, Article ID 7191826: 8 pages.

10. Bayaomi, Mohamed M., Wakeel, Jamal Saleh. Impacts of Exercise programs on 
Hemodialysis Patients' Quality of Life and Physical Fitness. USA: Quality in Primary Care . 2015; 23 (4): 192-200

11. Black, J. M. \& Hawks, Jane Hokanson. Medical Surgical Nursing Clinical Management for Positive Outcome. Eighth Edition. Volume I. USA: Elseiver Saunder Company; 2009

12. Ouzouni, S., Kouidi, E., Sioulis, A., Grekas, D., \& Deligiannis, A. Effects of intradialytic exercise training on healthrelated quality of life indices in haemodialysis patients. Clinical Rehabilitation. 2009; 23(1): 53-63.

13. Li, M., Li, L., \& Fan, X. Patients having haemodialysis: physical activity and associated factors. Journal Of Advanced Nursing. 2010; 66(6): 1338-1345.

14. Silbiger \& Neugarten. Gender and human chronic renal disease. Gend Med. 2008; 5 Suppl A: S3-S10 2008

15. Smart, N., \& Steele, M. Exercise training in haemodialysis patients: A systematic review and meta-analysis. Nephrology. 2011: 16(7); 626-632

16. Jeager, J., Mehta, R. Assessment of Dry Weight in Hemodialysis. Journal of the American Society of Nephrology. 1999: vol. 10 no. 2; 392-403

17. Riyanto, Hubungan Antara Penambahan Berat Badan Di Antara Dua Waktu Hemodialisis (Interdialysis Weight Gain = Idwg) Terhadap Kualitas Hidup Pasien Penyakit Ginjal Kronik Yang Menjalani Terapi Hemodialisis Di Unit Hemodialisa Ip2k Rsup Fatmawati [Tesis].Jakarta, Universitas Indonesia; 2011

18. Ningsih, Endang Sri P; Agus Rahmadi; Hammad, Tingkat Kepatuhan Pasien Gagal Ginjal Kronik Dalam Pembatasan Cairan Pada Terapi Hemodialisa.Jurnal Ners. 2012: 7; 25-31

19. Craven, Ruth F., Hirnle, Constance J. Fundamentals of Nursing : Human Health and Fungtion. Fourth Edition. USA : Lippincott Williams \& Wilkins; 2003

20. Potter P. A \& Anne G Perry, Fundamental Keperawatan (Ed.7). Jakarta: Salemba Medika; 2009

21. Grange, S., Hanoy, M., Roy, F. L., Guerrot, D., Godin, M. Monitoring of hemodialysis quality of care indicator: why is it important?. BMC Nephrology. 2013: $14 ; 109$ 